\title{
DST em mulheres que realizaram exame citopatológico no Centro de Saúde de Passo Fundo-RS
}

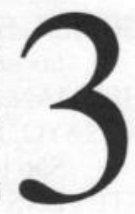

\section{RESUMO}

O presente estudo objetivou detectar DST em mulheres que realizaram exame citopatológico no Centro de Saúde de Passo Fundo, verificando a existência de associação entre as DST e o grau de escolaridade, estado civil, método contraceptivo, freqüência de relações sexuais por semana, faixa etária das mulheres. Os dados foram coletados nas fichas preenchidas no momento da coleta do exame citopatológico e analisado através do teste " $U$ " de Mann-Whitney com um nível de significância de 0,05 . Os resultados apontam Trichomonas vaginalis e Gardnerella vaginalis como agentes etiológicos responsáveis pelas DSTs. Constatou-se associação estatisticamente significante entre mulheres com DSTs e as variáveis descritas acima, com exceção da variável número de parceiros no último ano. Em vista desses resultados serem limitados, pela pequena incidência de DSTs, recomenda-se a continuidade do estudo, para confirmar resultados que apontam a necessidade de ações educativas à população periférica do município como estratégia de prevenção das DSTs.

* Mestre em enfermagem na saúde da mulher. Professora titular III da disciplina de enfermagem na saúde da mulher I e II. Universidade de Passo Fundo.

** Acadêmica do IX semestre de enfermagem da Universidade de Passo Fundo.

Recebido em 13.08.00

Aprovado em 03.09.00 


\section{Unitermos:}

- Sexualidade

- DSTs

- Saúde da Mulher

- Educação Sexual

\section{INTRODUÇÃO}

As doenças sexualmente transmissíveis por serem relativamente comuns e passarem despercebidas pela maioria das mulheres, acabam sendo subestimadas e, conseqüentemente, subdiagnosticadas. Além disso, por acometer igualmente mulheres de diferentes raças e classes sociais, não recebem dos serviços de saúde a devida atenção. Em decorrência, verifica-se um aumento crescente no número de casos de doenças sexualmente transmissíveis nas mulheres que buscam o serviço de prevenção de câncer de cérvice uterino e de seus parceiros.

Os primeiros relatos sobre as doenças sexualmente transmissíveis DST foram encontrados na civilização mesopotâmica ( $\mathrm{III}^{\mathrm{Q}}$ milênio antes de Cristo) escritos cuneiformes em placas de argila, fornecendo informações sobre a gonorréia (Linhares, 1993).

As DST por serem múltiplas, latentes, assintomáticas e passarem freqüentemente despercebidas, continuam a ocorrer em níveis inaceitavelmente altos (Burros \& Ferris, 1996); elas são consequiência da atuação de mais de 40 agentes (bactérias, fungos, protozoários e artrópodes) que se manifestam isoladamente ou em associações (Linhares apud Belda, 1995). A maioria dos casos de DST está restrito à pessoas sexualmente ativas (adolescentes e adultos jovens com idade entre 15 e 34 anos (Naud et al, 1993).

$\mathrm{O}$ mau preparo dos profissionais de saúde e educação, as péssimas atuações dos serviços públicos, a baixa condição sócio-econômica e a desinformação sobre educação sexual, está ocupando locais de destaque na concorrência para elevar cada vez mais o número de casos de pessoas contaminadas por DST (Passos, 1990). As pessoas que mantém vida sexual ativa devem estar conscientizadas que estão vivendo numa era onde o número de indivíduos infectados pelas DST e assintomáticos é desconhecido e considerar todas as pessoas potencialmente contaminadas (Yazlle et al, 1988), e a partir disso utilizar o método de barreira, sendo que o condon de latéx masculino ou feminino é a forma mais eficaz de prevenção quando usados correta e sistematicamente (Best, 1999).

Alguns trabalhos realizados no Brasil mostram que, em determinadas regiões do país, a maior parte dos casos de DST são atendidos por balconistas de farmácias, sendo que esses casos são, na sua maioria, homens, já que as mulheres, geralmente assintomáticas, ficam sem diagnóstico e tratamento. A nível mundial, a cada ano surgem 250 milhões de novos casos de DST, o que representa mais de meio milhão de casos por dia; e em países em 
desenvolvimento, em cada 10 mulheres uma, pelo menos, está infectada por uma DST (Moherdavi, 1998).

A atuação integrada e coordenada de instituições governamentais, organizações não governamentais e iniciativa privada, poderá garantir, a curto prazo, a interrupção da transmissão das DST e a prevenção de novos casos dessas doenças, através de uma assistência integrada às DST em unidades básicas de saúde com o pessoal treinado para o atendimento adequado, com disponibilidade de testes rápidos e de medicação apropriada e gratuita; e também orientando e educando sobre as DST no sentido de produzir mudanças positivas de atitudes e comportamentos das pessoas (Moherdavi, 1998).

Ao realiza exame citopatológico constata-se a presença de doenças sexualmente transmissíveis tais como: trichomonas vaginalis, gardnerella vaginalis, $H P V$, candida albicans, chlamydia trachomatis. Então, decidiuse desenvolver esta pesquisa no intuito de verificar se existe relação significativa entre as DST e as seguintes variáveis: idade na realização do exame, método contraceptivo usado no momento da coleta, freqüência de relações sexuais por semana, estado civil, escolaridade, número de parceiros no último ano. Ao mesmo tempo, objetivou-se identificar as DST mais freqüentes, com vistas a ampliar e aprofundar o conhecimento sobre o tema e melhorar, conseqüentemente, as orientações quanto à prevenção e à redução no número de casos entre elas e seus parceiros.

\section{METODOLOGIA}

Este estudo descritivo foi desenvolvido no departamento de ginecologia do Centro de Saúde de Passo Fundo nos meses de dezembro de 1999 e fevereiro de 2000 . A escolha dessa unidade sanitária deu-se pelo fato de abranger as mulheres dos diversos setores periféricos do município.

A amostra foi constituída por cem mulheres que realizaram o exame citopatológico naquele serviço, incluídas no estudo por amostragem não probabilística intencional de casos típicos, observando-se a sua anonimicidade.

A coleta de dados foi autorizada pelo Secretário Municipal de Saúde e Meio Ambiente, e realizada por ocasião da revisão do arquivo de fichas, que são preenchidas no momento da coleta de citopatológico contendo as seguintes variáveis:

- Idade na realização do exame;

- Número de parceiros no último ano;

- Escolaridade;

- Estado civil;

- Método contraceptivo;

- Freqüência de relações sexuais por semana.

A análise dos resultados foi efetuada a partir das hipóteses, utilizando-se o teste "U" de Mann-Whitney com significância ao nível de 0,05 entre as variáveis e a presença ou ausência de DST. 


\section{RESULTADOS E DISCUSSÃO}

Das 100 mulheres que realizaram o exame, apenas $10 \%$ apresentaram DSTs. Dessas, $6 \%$ eram portadoras de Tricomoníase e $4 \%$ de Gardnerella vaginalis, como pode ser observado na Figura 1.

$\mathrm{O}$ agente etiológico trichomonas vaginalis foi identificado por Donné em 1936. É um protozoário flagelado oval e fusiforme, medindo de 10 a $24 \mu \mathrm{m}$ de comprimento e 5 a $10 \mu \mathrm{m}$ de espessura. Possui quatro flagelos anteriores, axóstilo e membrana ondulante. O habitat natural é a vagina, mas pode ser encontrado na uretra, bexiga, ureteres, canal cervical, cavidade uterina, glândula de Skene e Bortholin; cresce melhor em condições de anaerobiose e em meio úmido com $\mathrm{PH}$ de 4,9 a 7,5 à temperatura de 35 a 37 graus ${ }^{\circ} \mathrm{C}$. A mulher funciona como reservatório e em casos de infecção crônica, o homem também atua como reservatório. Além da transmissão sexual, Fonseca \& Passos (1990) afirmam que é possível, em condições especiais, a transmissão por meio de banheiros públicos, saunas, toalhas de banho, material para exame ginecológico indevidamente esterilizado; contudo, estes dados são estatisticamente desprezíveis, sendo que o contato com fômites é a principal via de transmissão, quando não existe o contato sexual. Hammil (1989) demonstrou a vivalidade do agente infectante por mais de seis horas em ladrilhos de banheiros e por mais de 25 horas em toalhas infectadas.

Os achados no exame ginecológico dependem da severidade da doença. Geralmente ocorre hiperemia e edema na vulva, observando-se acentuado aumento no conteúdo vaginal. Ao exame especular, observa-se intensa hiperemia na vagina e cérvice, sendo que freqüentemente, observa-se colo "com aspecto de morango". A coloração do conteúdo vaginal pode ser amarelada, esverdeada, esbranquiçada ou acizentada, de consistência espessa ou fluída.

Embora o trichomonas vaginalis seja freqüentemente visto em esfregaços corados pelo método Papanicolau apresenta uma sensibilidade de apenas 60 a $70 \%$ quando comparado com o exame a fresco, e não raramente ocorre falso-positivo. Em mulheres assintomáticas, a detectação do trichomonas vaginalis tem sido feita através desse teste (Sobel, 1990).

$\mathrm{O}$ trichomonas vaginalis é o mais freqüente patógeno encontrado nas doenças sexualmente transmissíveis. Os índices de prevalência mundial registram taxas que oscilam de $5 \%$ a $65 \%$ entre as mulheres examinadas em clínicas ginecológicas, enquanto que a prevalência varia de $8 \%$ a $88 \%$ entre as mulheres submetidas a exame periódicos em serviços de diagnóstico de doenças sexualmente transmitidas. Estima-se que seis milhões de mulheres nos EUA, o que corresponde a cinco por cento da população, e 180 milhões de mulheres no mundo são infectadas anualmente, correspondendo a um terço de todas as vaginites diagnosticadas. No Brasil, pela falta de controle sanitário e de notificações, não se tem dimensão em sua amplitude, por isso a importância de seu estudo bem como da divulgação dessa patologia (Consolaro et al, 1999). Nesse estudo, a maioria das mulheres que realizaram o exame citopatológico no Centro de Saúde residia em regiões periféri- 
cas da cidade de Passo Fundo e pertencia a um nível sócio-econômico baixo. Segundo Carli (1995), a prevalência de tricomonas é alta entre os grupos de nível sócio-econômico baixo e a maior prevalência de tricomoníase é observada nas mulheres entre a segunda e a terceira década de vida, o que é confirmado neste trabalho, no qual as portadoras estavam dentro da faixa etária de 20 e 24 anos e 35 e mais anos de idade. Entre as mulheres que realizavam o exame citopatológico $6 \%$ apresentaram tricomoníase diagnosticadas por ocasião deste exame, só o fazendo uma vez cada ano no momento do exame preventivo de câncer de colo uterino, supondo-se assim, que essas mulheres eram assintomáticas e, por isso, não procuraram ajuda. Para Carli (1995), a forma assintomática representa $15 \%$ a $20 \%$ dos casos, sendo um achado laboratorial decorrente de exame de rotina aconselhado na prevenção do câncer de colo de útero, feito anualmente (Júnior \& Siqueira, 1999).

O outro agente etiológico relacionado às DST diagnosticadas nas mulheres que realizaram o exame citopatológico foi a gardnerella vaginalis, que é uma bactéria gram-negativa, pequena, pleomórfica, de metabolismo anaeróbico, facultativo. A relação entre gardnerella vaginalis e doença não é um simples fenômeno de causa-efeito; o micro organismo é um constituinte relativamente comum da flora vaginal, pois apenas pequeno número de mulheres que abrigam a bactéria tem queixa de fluxo e odor desagradável, sem clínica para os sinais inflamatórios de genitália, principalmente em área de mucosa (Naud, 1997). Os dados das pacientes portadoras de gardnerella vaginalis, neste estudo, mostram que a maioria delas não teve relação sexual no último ano. A partir disso, deduz-se que estas mulheres são assintomáticas confirmando a afirmação de Naud (1997).

Os fatores que governam a expressão clínica da gardnerella vaginalis são pouco conhecidos, porém atribui-se papel importante à magnitude de replicação da bactéria; segundo estudos bacteriológicos quantitativos, o estado da doença está associado com quantidades de bactérias por grama de fluído vaginal (Linhares, 1993). A gardnerella vaginalis foi isolada no conteúdo vaginal de meninas com idade inferior a 9 anos e em adolescentes que nunca tiveram relacionamento sexual (Di Paola, 1980).

$\mathrm{O}$ exame especular é o método propedêutico mais útil. O conteúdo vaginal tem aspecto homogêneo e sua coloração é cinzenta ou amareloclara, apresentando raramente prurido ou ardor, sendo que as mulheres afetadas, em geral, não apresentam inflamação vaginal ou vulvar.

A gardnerella vaginalis, junto a bacteróides e cocos anaeróbios, causa uma vaginite e/ou uma cervicite nas mulheres, alterando o $\mathrm{PH}$ e a flora vaginal.

Os dados da Figura 2 mostram que não existe associação significante, ao nível de 0.05 entre as mulheres que são portadoras de DST e as que não são portadoras, em relação ao número de parceiros no último ano, sugerindo assim, que as pacientes portadoras de DST que tiveram um parceiro no último ano possam ter sido contaminadas por parceiro com mais de uma parceira sexual, confirmando que as DST acometem indivídos que variam freqüentemente de parceiros (Linhares apud Belda, 1995). Segundo Lowndres (1999), freqüentemente a mulher não pode reduzir o número 
de parceiros sexuais, porque sua exposição depende de fato, do número de parceiros sexuais do seu parceiro.

Em relação a escolaridade (Figura 3) embora não se tenha a comparação estatística, observou-se que o maior número de mulheres com DST, são mulheres com baixo grau de instrução, ou seja, primeiro grau incompleto, havendo associação significante, ao nível de 0.05 entre as mulheres que são portadoras de DST e as que não são portadoras em relação a escolaridade, confirmando-se assim, que o aumento na incidência das DST que vem ocorrendo em um grande número de países é atribuído à ausência de educação em saúde (Passos \& Fonseca, 1990).

A Figura 4 mostra que existe associação significante, ao nível de 0,05 entre as mulheres que são portadoras de DST e as que não são portadoras em relação ao estado civil. Cabe ressaltar que em virtude da baixa incidência de DST nas mulheres que realizaram exame citopatológico no período de desenvolvimento do estudo, não foi possível aplicar testes estatísticos para verificar a associação entre as variáveis. Dessa forma, no grupo das portadoras de DST, pode-se afirmar que não existe relação entre as DST e o estado civil, tendo em vista que a incidência da doença distribui-se igualmente entre as mulheres casadas, solteiras e viúvas.

Existe associação significante, ao nível de 0,05 entre as mulheres que são portadoras de DST e as que não são portadoras em relação ao método contraceptivo. Constatou-se, como demonstra a Figura 5, que o método mais eficaz foi o condon masculino e feminino, pois este método, segundo Lay (1994), representa o único método comprovado que protege contra as DST bacterianas e virais quando usado de maneira correta e sistemática, sendo que outros métodos contraceptivos proporcionam pouca ou nenhuma proteção.

Na Figura 6 observa-se que existe associação significante, ao nível de 0,05 entre as mulheres que são portadoras de DST e as que não são portadoras em relação a frequiência de relações sexuais. Observou-se que o maior número de mulheres com DST, são aquelas que não tem nenhuma relação sexual por semana, sugerindo que estas mulheres sejam assintomáticas crônicas.

Existe associação significante, ao nível de 0,05 entre as mulheres que são portadoras de DST e as que não são portadoras em relação a idade. Na Figura 7 constatou-se que as faixas etárias com maior incidência de DST está entre a segunda e terceira década de vida, conforme afirma Carli (1995).

\section{CONCLUSÃO}

Neste estudo constatou-se que as mulheres que realizaram exame citopatológico no Centro de Saúde de Passo Fundo, nos meses de dezembro de 1999 e fevereiro de 2000 , dez por cento (10\%) eram portadoras de doenças sexualmente transmissíveis, sendo que as doenças encontradas foram tricomoníase e Gardnerella vaginalis. 
O estudo confirmou que existe associação significante ao nível de 0,05 entre as mulheres portadoras de DST e as que não são portadoras, em relação às seguintes variáveis:

- Grau de escolaridade;

- Estado civil;

- Método contraceptivo;

- Freqüência de relações sexuais por semana;

- Faixa etária.

Quanto a variável "número de parceiros no último ano", constatou-se que não existe associação significante ao nível de 0,05 entre as mulheres portadoras de DST e as que não são portadoras.

A partir desse estudo, sugere-se a passagem de informações sobre os sinais, sintomas e, principalmente, a prevenção das DST, no momento da coleta de citopatológico, e também por meio de palestra educativas e informais para grupos de mulheres nos bairros periféricos da cidade onde estas são residentes.

Recomenda-se para outros pesquisadores, ao dar continuidade a esta pesquisa que aumentem a amostra, pois encontrou-se dificuldades em virtude do pequeno número de casos de DST em aplicar o teste de Qui-quadrado recomenda-se, então o teste de "U" Mann-Whitney para amostras pequenas. A ampliação da amostra permitirá a confirmação ou não destes achados.

\section{REFERÊNCIAS BIBLIOGRÁFICAS}

BEST, Kim. El Buen Asesoramiento es Vital para Clientes com ETS. Rev. Network en español, family Health international, v. 19, n. 2, p. 23-24, invierno, 1999.

CARLI, Geraldo Attílio De. Trichomonas. In: NEVES, David Pereira (org.). Parasitologia Humana. 9. ed. São Paulo: Atheneu, 1995. p. 121.

CONSOLARO, Márcia Edilaine et al. Estudo da tricomoníase e a sua abordagem no diagnóstico colpológico. Rev. Brasileira da Análises Clínicas, v. 31, n. 1, p. 25-28. 1999.

DI PAOLA. In: PIATO, Sebastião. Tratado de ginecologia. São Paulo: 1997. p. 186-188.

HAMMIL, H. A. Vaginose bacteriana, candidiose e tricomonas. In: HALBE, Hans Wolfgang (org.). Tratado de ginecologia. 2. ed. São Paulo: Roca, 1993, v. 1. p. 879.

JUNIOR, Manuel Fernando Queiroz dos Santos; SIQUEIRA, Luiz Fernando de Góes. Tricomoníase. In: CIMERMAN, Benjamin; CIMERMAN, Sérgio (org.). Parasitologia Humana. São Paulo: Atheneu, 1999. p. 37.

LINHARES, Iara Moreno et al. Vaginose bacteriana, candidiose e tricomoníase. In: HALBE, Hans Wolfgang (org.). Tratado de ginecologia. 2. ed. São Paulo: Roca, v. 1, 1993. p. 876.

LINHARES, Iara Moreno. Prevenção e controle das doenças sexualmente transmissíveis. In: HALBE, Hans Wolfgang (org.). Tratado de ginecologia.

2. ed. São Paulo: Roca, 1995. p. 96. 
LOWNDRES, Catherine M. Doenças sexualmente transmissíveis na mulher. In: GIFFIN, Karen; COSTA, Sarah Hawker (org.). Questões da Saúde Reprodutiva. Rio de Janeiro: Fiocruz, 1999. p. 253-274.

MOHERDAVI, Fabio. As doenças sexualmente transmissíveis no Brasil. Rev. Jornal Brasileiro de Doenças Sexualmente Transmissíveis. Niterói, v. 10, n. 4, p. 5-6, 1998.

NAUD, Paulo et al. Gestação e doenças sexualmente transmissíveis. In: FREITAS, Fernando et al. Rotinas em obstetrícia. 3. ed. Porto Alegre: Artes Médicas, 1997. p. 315.

NAUD, Paulo et al. Doenças sexualmente transmissíveis. In: FREITAS, Fernando; MENKE, Carlos Henrique; RIVOIRE, Valdemar; PASSOS, Eduardo Pandolfi. Rotinas em ginecologia. 3. ed. Porto Alegre: Artes Médicas, 1993. p. 85 .

PASSOS, Mauro Romero Leal. Jornal Brasileiro de Doenças Sexualmente Transmissíveis: Epidemiologia das DSTs. Rev. DST - Jornal Brasileiro de Doenças Sexualmente Transmissíveis. Rio de Janeiro, v. 2, n. 2, 3, 4. p. 35-36, abr./dez. 1990.

PASSOS, Mauro Romero Leal; FONSECA, Cristiane Guimarães. Tricomoníase. Jornal Brasileiro de Doenças Sexualmente Transmissíveis. Rev. DST - Jornal Brasileiro de Doenças Sexualmente Transmissíveis. Rio de Janeiro, v. 2, n. 2, 3, 4. p. $52-53$, abr./dez. 1990.

SOBEL, J. D. Vaginose bacteriana, candidíase e tricomoníase. In: HALBE, Hans Wolfgang (org.). Tratado de ginecologia. 2. ed. v. 1. São Paulo: Roca, 1993. p. 879.

FIGURA 1 Doenças sexualmente transmissíveis diagnosticadas em mulheres que realizaram exame citopatológico no Centro de Saúde de Passo Fundo no período de dezembro de 1999 e fevereiro de 2000

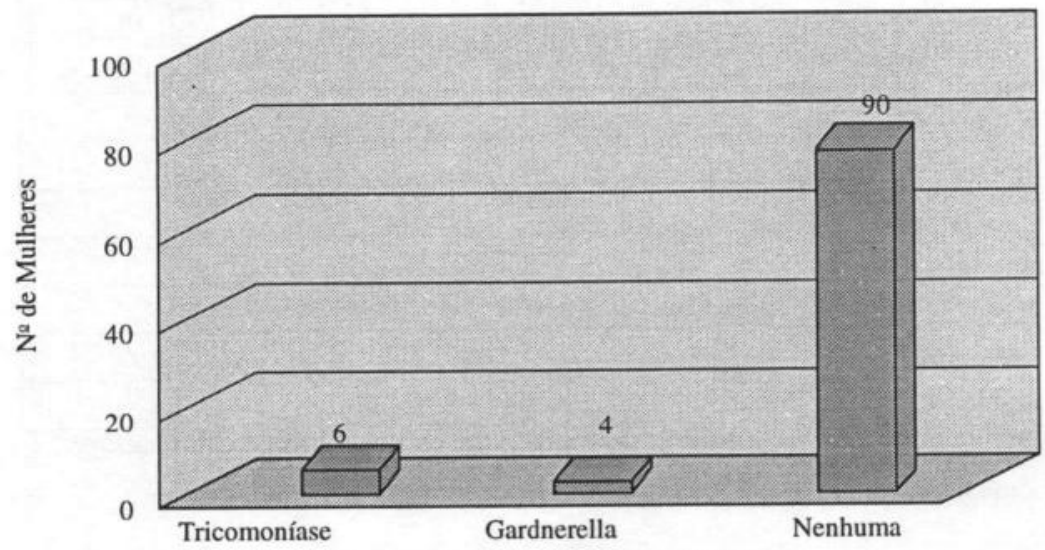

Doenças Sexualmente Transmissíveis 
FIGURA 2 Distribuição das mulheres, com e sem DST, conforme o número de parceiros no último ano, no Centro de Saúde de Passo Fundo, em dezembro de 1999 e fevereiro de 2000

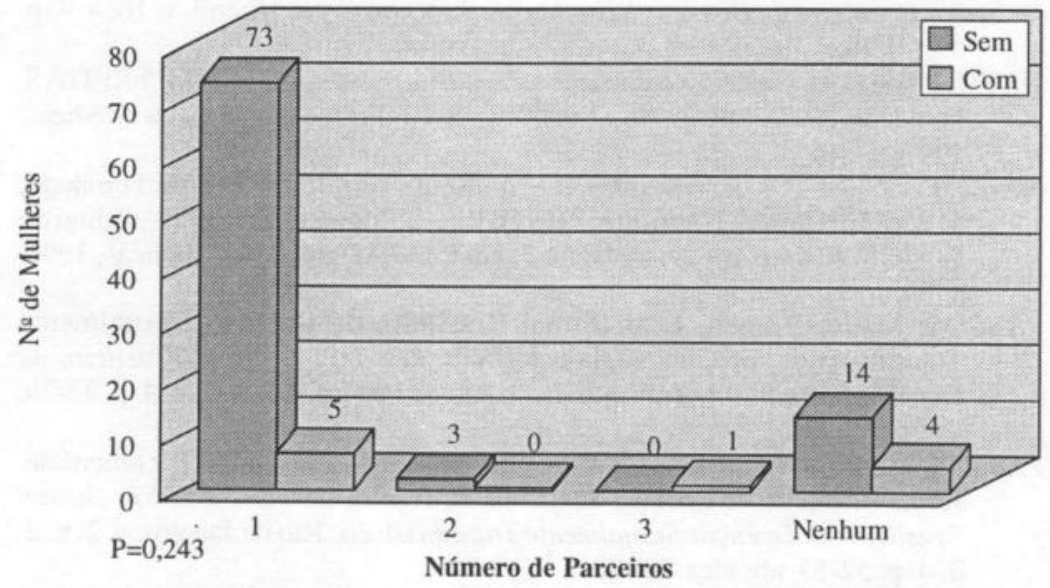

FIGURA 3 Distribuição das mulheres com e sem DST, conforme a escolaridade, no Centro de Saúde de Passo Fundo, em dezembro de 1999 e fevereiro de 2000

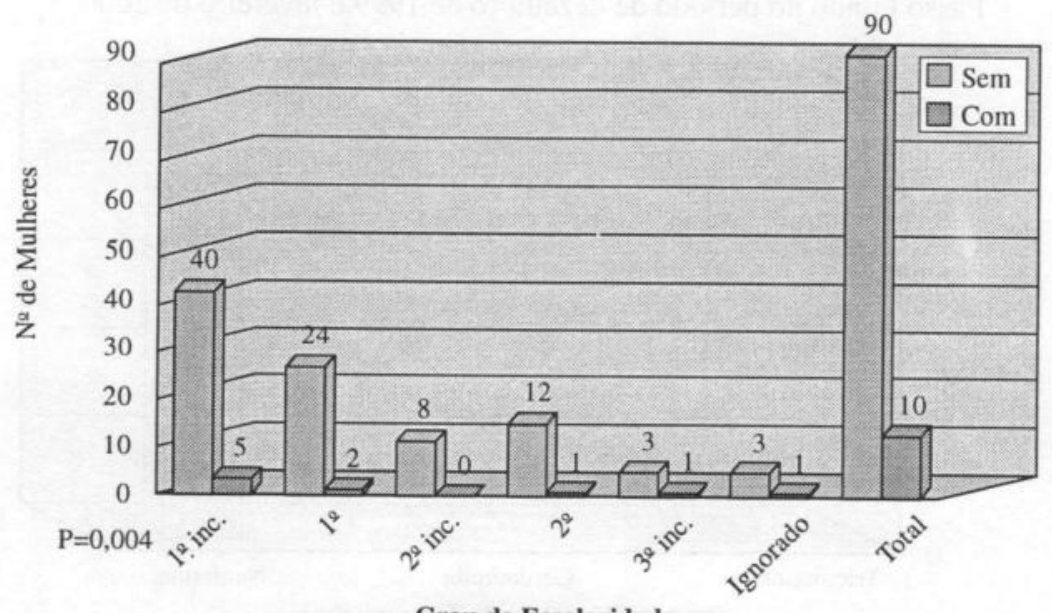

Grau de Escolaridade 
FIGURA 4 Distribuição das mulheres com e sem DST, segundo o estado civil, no Centro de Saúde de Passo Fundo, em dezembro de 1999 e fevereiro de 2000

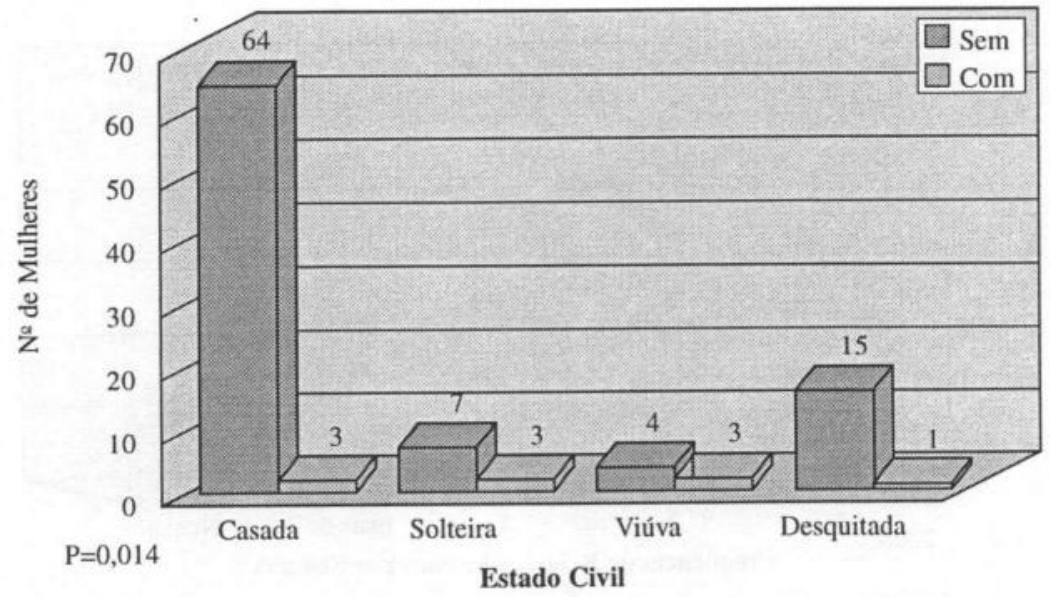

FIGURA 5 Distribuição das mulheres com e sem DST, segundo o método contraceptivo, no Centro de Saúde de Passo Fundo, em dezembro de 1999 e fevereiro de 2000

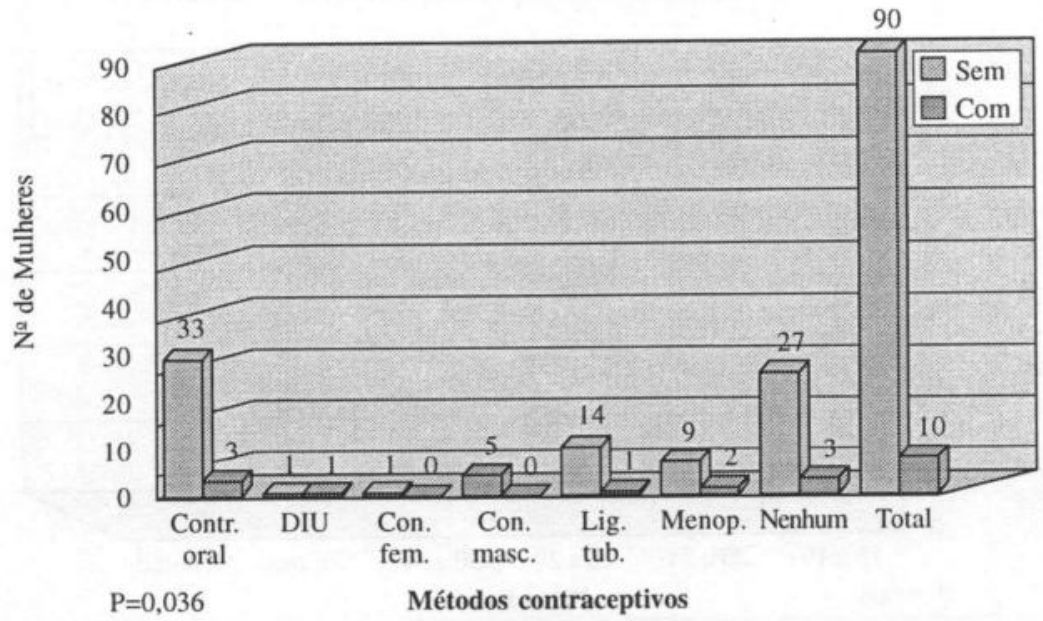


FIGURA 6 Distribuição das mulheres com e sem DST, conforme o número de relações sexuais por semana. Centro de Saúde de Passo Fundo em dezembro de 1999 e fevereiro de 2000.

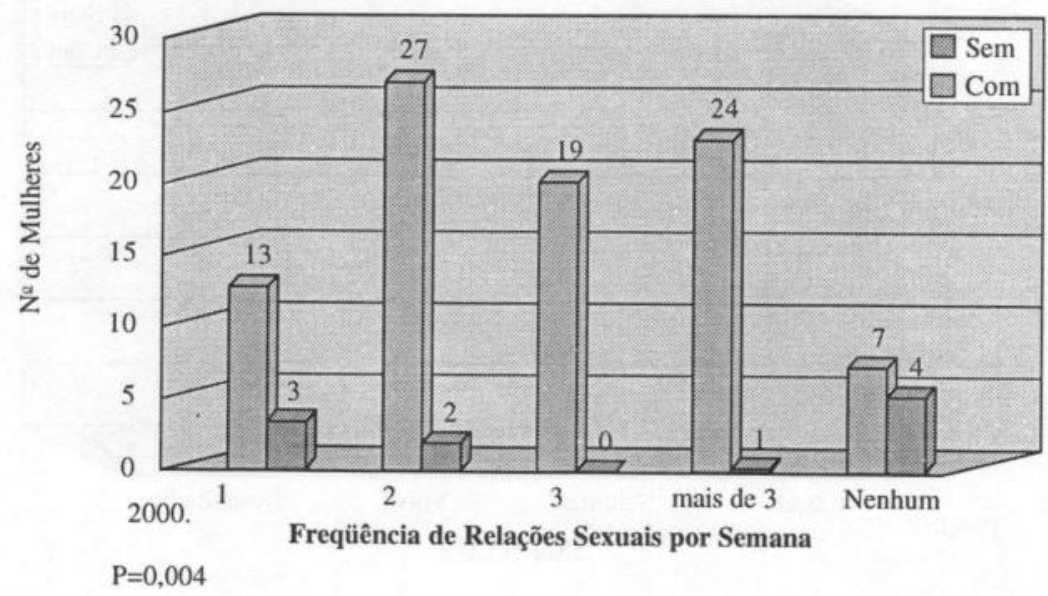

FIGURA 7 Distribuição das mulheres que realizaram exame citopatológico com e sem DST, conforme faixa etária. Centro de Saúde de Passo Fundo, em dezembro de 1999 e fevereiro de 2000.

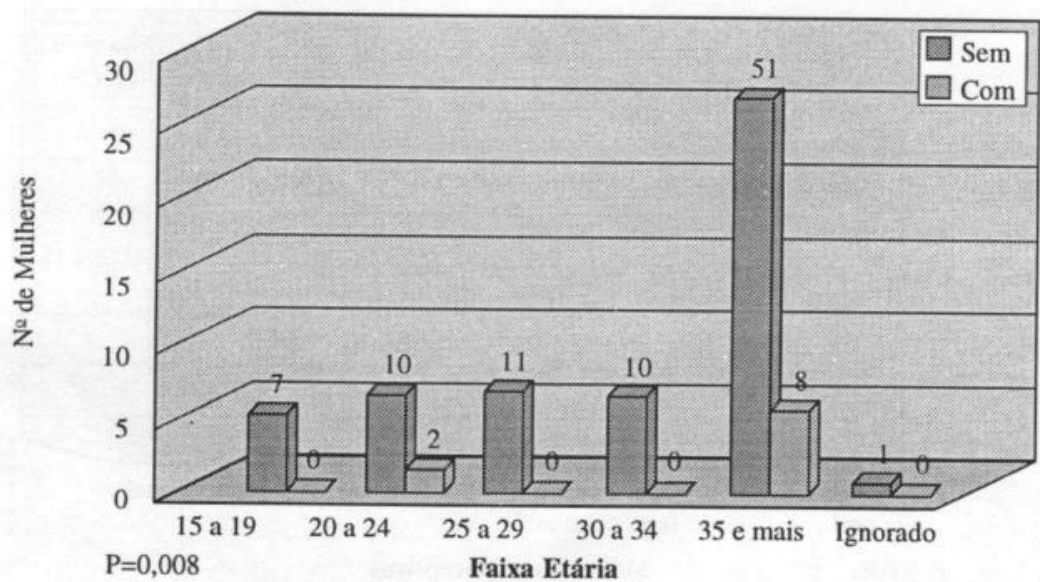

